Radioprotection, vol. 44, $\mathrm{n}^{\circ} 5$ (2009) 487-491

(C) EDP Sciences, 2009

DOI: $10.1051 /$ radiopro/20095090

\title{
Effect of low-dose chronic gamma exposure on growth and oxidative stress related responses in Arabidopsis thaliana
}

\author{
H. Vandenhove ${ }^{1}$, N. Vanhoudt ${ }^{1}$, J. Wannijn ${ }^{1}$, M. Van Hees ${ }^{1}$ and A. Cuypers ${ }^{2}$ \\ ${ }^{1}$ Belgian Nuclear Research Centre, Biosphere Impact Studies, 2400 Mol, Belgium \\ ${ }^{2}$ Hasselt University, Environmental Biology, Agoralaan Building D, \\ 3590 Diepenbeek, Belgium
}

\begin{abstract}
The biological responses induced by low-dose chronic gamma exposure of hydroponically grown Arabidopsis thaliana, irradiated during a full life cycle (seed to seed) were investigated. Applied dose rates were 2300,375 and $85 \mu \mathrm{Gray} \mathrm{h}^{-1}$. Plants (roots and shoots) were harvested after 24 day (inflorescence emergence), at 34 days ( $\sim 50 \%$ of flowers open) and at 54 days (silice ripening). Gamma exposure significantly reduced root weight compared to the control but no clear effect of dose rate level on root dry weight was observed. Leaf weight was significantly reduced at the highest irradiation level, only after 54 days exposure. ED-10 was estimated at $10 \mu \mathrm{Gy} \mathrm{h}^{-1}$. Seed germination was not affected by gamma irradiation. For several of the stress enzymes studied enzyme capacity was generally stimulated at the low and intermediate gamma irradiation level compared to the control and highest irradiation level. No pattern was observed in concentration or reduction state of the non-enzymatic antioxidants, ascorbate and glutathione. Lipid peroxidation products in leaves were present highest at full flowering and decreased with exposure level at this growth stage. At the other two growth stages, lipid peroxidation products were unaffected by gamma treatment.
\end{abstract}

\section{INTRODUCTION}

Environmental adversity like radiation often leads to the increase in the formation of highly reactive oxygen species (ROS) [1] which may cause oxidative stress, a disturbance of the cellular redox status. This may in turn result in lower plant vigour through the oxidation of proteins, cell membranes and DNA damage. Organisms possess several antioxidative defence mechanisms to control the redox status of the cell $[2,3]$ which is essential for normal physiological and biochemical functioning. Resistance to such conditions may be correlated with enzymes in oxygen detoxification. The steady state level of ROS in different cellular compartments is determined by the interplay between multiple ROS producing pathways and ROS-scavenging mechanisms. ROS and other oxidants are balanced against the oxidative defence system, which is composed of enzymes as well as metabolites as ascorbate (AsA) and glutathione (GSH). Action of these metabolites with catalases (CAT), superoxide dismutases (SOD) and peroxidases (PX) makes up the cells antioxidative power that maintains the cellular homeostasis within certain limits [4]. All subcellular compartments contain specific antioxidative enzymes or metabolites which are coordinated and controlled by underlying regulatory mechanisms. The ascorbate-glutathione cycle plays a central role in the antioxidant defence mechanism in plant cells [3, 4]. Antioxidants such as AsA and GSH are found in very high concentrations in chloroplasts and other cellular compartments and mutants with suppressed AsA levels are more sensitive to pathogenic attack and abiotic stress.

The objective of this study is to evaluate the biological responses induced by low-dose chronic gamma exposure of Arabidopsis thaliana, irradiated during a full life cycle (seed to seed). This study aimed at developing dose-effect relationships, considering endpoints important for the survival of a species (morbidity, reproduction) or selected to identify and unravel effects induced at sub-cellular level. 


\section{MATERIALS AND METHODS}

\subsection{Experimental set up}

Arabidopsis thaliana (Columbia ecotype) was hydroponically grown (modified Hoagland solution) and exposed to a ${ }^{137} \mathrm{Cs}$ gamma source. Applied dose rates were 2339 (H), 370 (M) and 84 (L) $\mu \mathrm{Gy} \mathrm{h}^{-1}$. For each exposure condition, including a control (C) treatment, 3 containers were prepared, each holding $811.5 \mathrm{ml}$ polyethylene tubes filled with rock wool on which seeds were placed. Exact doses were recorded with four thermoluminescence dosimeters per exposure scenario. Plants were grown under a $14 \mathrm{~h}$ photoperiod with a photosynthetic photon flux of $145 \mu \mathrm{mol} \mathrm{s}^{-1} \mathrm{~m}^{-2}$.

\subsection{Plant sampling and biometric measurements}

Plants were harvested after 24 days (inflorescence emergence), at 34 days ( $\sim 50 \%$ of flowers open) and at 54 days (silice ripening). At harvest, leaf, root and/or stem fresh weight was determined and samples were snap frozen in liquid nitrogen and stored at $-80^{\circ} \mathrm{C}$.

\subsection{Plant analysis}

Frozen root or leaf tissue was homogenised in ice-cold $0.1 \mathrm{M}$ Tris $\mathrm{HCl}$ buffer at $\mathrm{pH} 7.8$, containing $1 \mathrm{mM}$ EDTA, $1 \mathrm{mM}$ dithiotreitol and $4 \%$ insoluble polyvinylpyrrolidone. The homogenate was squeezed through a nylon mesh and centrifuged for 10 minutes at $20000 \mathrm{~g}$ and $4{ }^{\circ} \mathrm{C}$. The enzyme activity was measured in the supernatant at $25^{\circ} \mathrm{C}$. Guaiacol or syringaldazine peroxidase capacities (GPOD, SPOD, EC.1.11.1.7.) were measured according to Bergmeyer et al. [5] and Imberty et al. [6], respectively. Superoxide dismutase (SOD, EC 1.15.1.1) catalyses the conversion of superoxide radicals into dioxygen and hydrogen peroxide and is measured according to McCord and Fridovich [7]. Analysis of the glutathione reductase (GR, EC 1.6.4.2) capacity was based on the reduction of GSSG, using NADPH [5]. Analysis of the capacity of catalase (CAT, EC 1.11.1.6) was performed as described by Bergmeyer et al. [5]. Total ascorbate (AsA + DHA) and reduced ascorbate (AsA) contents were estimated according to Hodges et al. [8]. The amount of dehydroascorbate (DHA) was calculated from the difference between the total and the reduced ascorbate. Total glutathione (GSH + GSSG) and glutathione disulphide (GSSG) contents were measured by the method of Anderson [9]. The amount of reduced glutathione (GSH) was calculated from the difference between the total glutathione and GSSG.

The malondialdehyde content of plant leaves was used as a measure of lipid peroxidation and was assessed following Dinshda et al. [10]. The DNA integrity of leaves and roots was analysed with the neutral comet assay according to Koppen [11] with slight modifications. Germination was tested on seeds collected after 54 days of exposure. For each treatment 100 seeds were placed on Petri dishes filled with agar. Growth post-emergence was followed for another 5 days.

\subsection{Statistical analysis}

Statistical analysis of data was performed with the statistical software Statistica for Windows [2]. For all parameters, the Kolmogorov-Smirnov test was used to test if residuals were distributed normally. Statistical analyses were performed using an ANOVA test. Mean values of treatments were compared using Tukey's multiple range tests.

\section{RESULTS AND DISCUSSION}

\subsection{Gross plant responses: growth and reproduction}

Gamma exposure significantly reduced root weight compared to the control at each sampling time (from 22 to $50 \%$ reduction) but no significant effect of dose rate level on root dry weight was observed. Leaf 
weight (Figure 1) and stem yield were significantly reduced at the highest irradiation level, only after 54 days of exposure.

The dose resulting in $10 \%$ decrease in growth was obtained following log-logistic estimation using Excel Bioassay97 [13]. ED-10 obtained were 15, 15, $13 \mu \mathrm{Gy} \mathrm{h}^{-1}$, respectively for leaf, root and stem fresh weight. These ED-10 estimates are largely comparable with the ED-10 estimates obtained from the linear regression equation relating the relative loss in leaf, root or stem fresh weight compared to the control with the logarithm of the dose rate. For the 3 growth parameters ED-10 were 11, 10 and $9 \mu \mathrm{Gy} \mathrm{h}^{-1}$, respectively. Obtained ED-10 values are equivalent to the predicted-no-effect dose rate of $10 \mu \mathrm{Gy} \mathrm{h}^{-1}$ proposed by the EC-ERICA project [14]. At this dose rate no effect at the population and ecosystem level is expected.
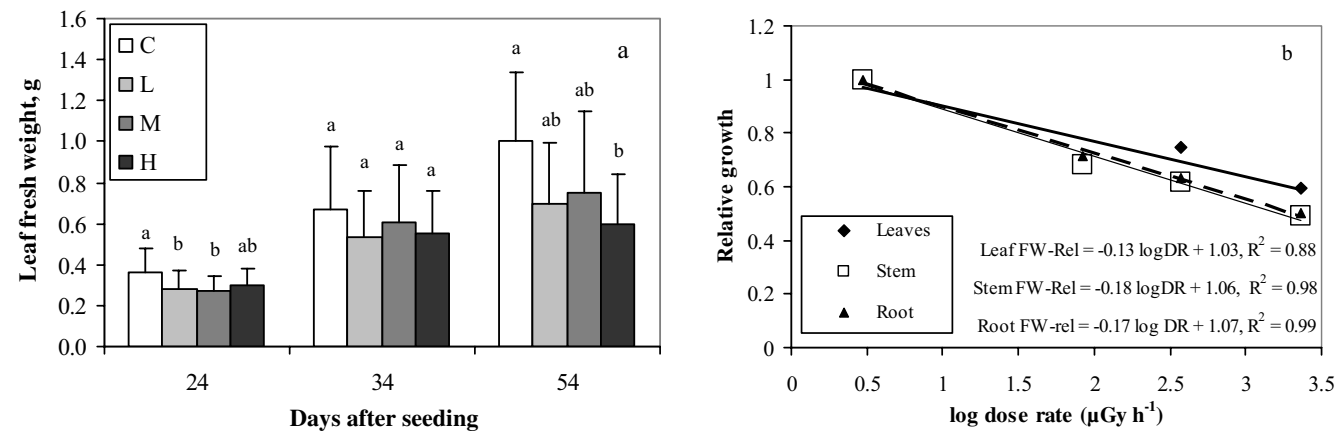

Figure 1. (a) Fresh weight of leaves (g) of Arabidopsis thaliana seedlings exposed for 24, 34 and 54-days at 84, 370 and $2339 \mu \mathrm{Gy} \mathrm{h}^{-1}$. Each point represents mean \pm SD of at least 8 biological replicates. Values with different letters are significantly different at $\mathrm{p}<0.05$; (b) Reduction in leaf, root and stem weight relative to the control treatment after 54 days' exposure in function of log dose rate (DR).

Seed germination and 5-days growth post-emergence was not affected by previous gamma irradiation. Wi et al. [15] found that plants exposed to relatively low doses of gamma rays (1-5 Gy) developed normally while the growth of plants irradiated at high doses (50 Gy) was seriously hampered. Growth of A. thaliana seedlings exposed to low-dose gamma rays (1-2 Gy) was even slightly increased compared to that of the control.

\subsection{Oxidative defence system}

Increased production of reactive oxygen derivates is provoked by both natural and stress situations. These highly cytotoxic species of oxygen can seriously disrupt normal metabolism through oxidative damage to cellular components. For their protection, plant cells are equipped with several reactive oxygen species detoxifying enzymes and with several non-enzymatic antioxidants, such as ascorbate and glutathione.

However, for the oxidative defence enzymes monitored hardly any significant differences in enzyme capacities with gamma exposure were observed and this as well for the roots as for the leaves (Figure 2). Enzyme capacities of leaves significantly increased with exposure duration (or with senescence) for SOD, SPOD (Figure 2), GPOD and CAT while for GLUR slightly higher capacities were observed at the first harvest (24 days). An increased $\mathrm{O}_{2}$ uptake during senescence of plant tissue has been reported [10] and $\mathrm{O}_{2}$ is used as substrate in the generation of free radicals. SOD, SPOD, GPOD, and CAT are direct quenchers of reactive oxygen species and enhanced activities may be induced to keep steady state levels of radicals. Dhinsda et al. [10] reported decreasing SOD and CAT capacities with senescence and they suggested that leaf senescence may be a consequence of cumulative membrane deterioration 

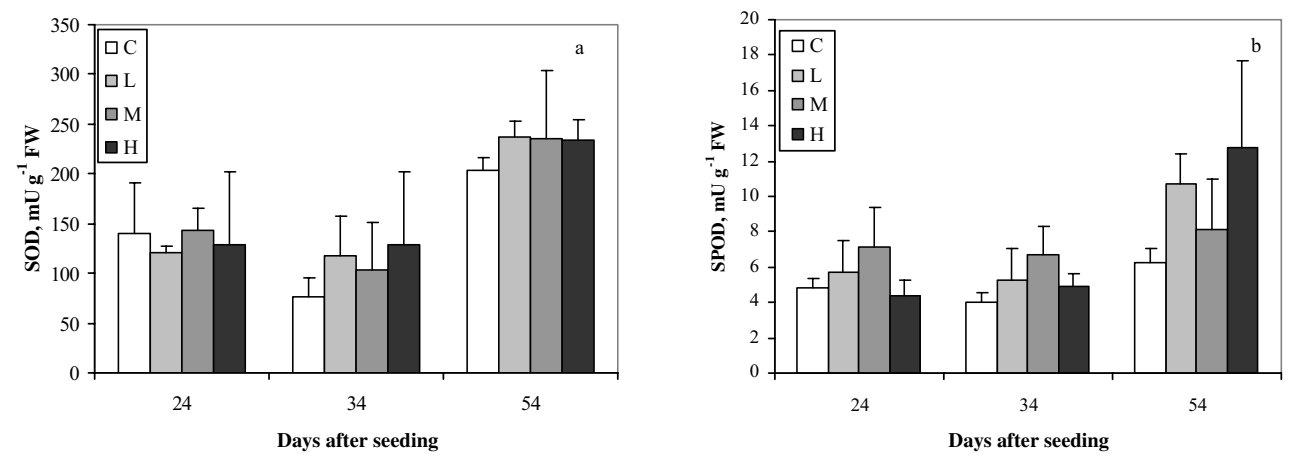

Figure 2. Enzyme capacities ( $\mathrm{mU} \mathrm{g}^{-1} \mathrm{FW}$ ) for superoxide dismutase (SOD) (a) and syringaldazine peroxidase (SPOD) in leaves of Arabidopsis thaliana exposed for 24, 34 and 54 days at 84, 370 and $2339 \mu \mathrm{Gy} \mathrm{h}^{-1}$. Each point represents mean $\pm \mathrm{SD}$ of at least 4 biological replicates.

due to increasing level of lipid peroxidation, induced by high levels of radicals, probably controlled by, amongst others, SOD and CAT activities.

We did not observe any significant effect of dose rate on the total levels of ascorbate and glutathione, nor on the concentrations of their reduced or oxidised forms in roots or leaves (Figure 3). The total ascorbate concentration and the concentration of oxidised ascorbate (dehydroxyascorbate, DHA) in the leaves increased towards the end of the experiment. A decrease in AsA/DHA ratio is observed pointing to a redox imbalance. We observed an overall significant increase in reduced glutathione levels in leaves towards the end of the experiment (Figure 3).
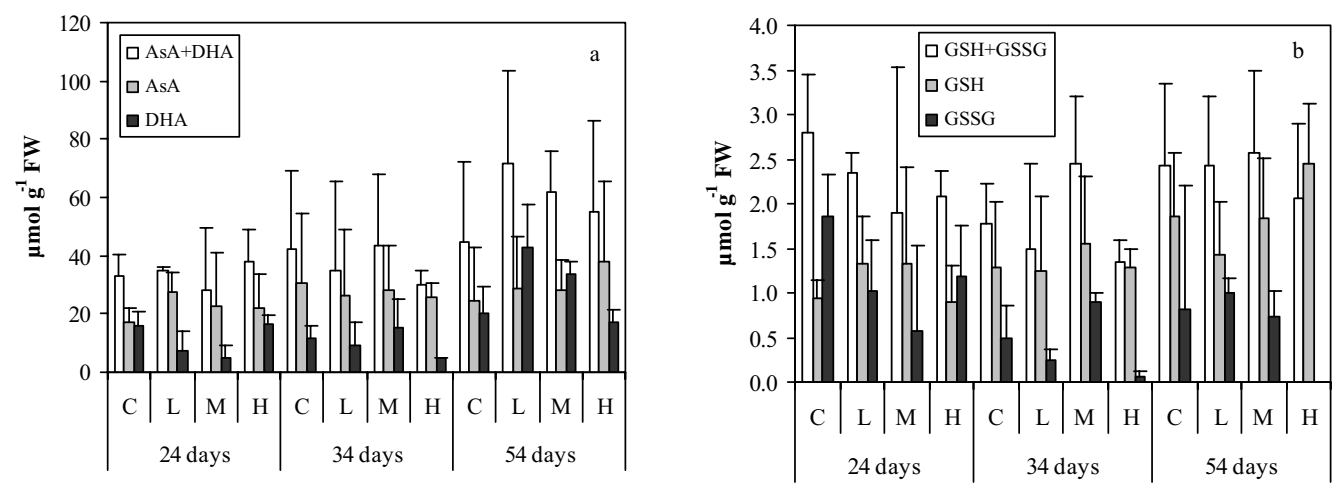

Figure 3. Total ascorbate, AsA (reduced ascorbate) and DHA (dehydroascorbate) ( $\mu \mathrm{mol} \mathrm{g}^{-1} \mathrm{FW}$ ) (a) and total glutathione, GSH (reduced glutathione) and GSSG (glutathione disulfide, expressed as glutathione equivalent) $\left(\mu \mathrm{mol} \mathrm{g}{ }^{-1} \mathrm{FW}\right)(\mathrm{b})$ in the leaves of A. thaliana exposed for 24,34 and 54 days at 84,370 and $2339 \mu \mathrm{Gy} \mathrm{h}^{-1}$. Each point represents mean $\pm \mathrm{SD}$ of at least 3 biological replicates.

The lipid peroxidation process, causing membrane disintegration, is believed to be initiated by free radicals. Lipid peroxidation products in leaves were expressed as TBA (thiobarbituric acid)-reactive compounds (mainly malondialdehyde, MDA). The concentration of membrane disintegration products was highest at full flowering (34 d). At this growth stage, MDA level decreased with exposure level, contrary to the expected. At the other two growth stages, MDA level was unaffected by gamma treatment. Lowest MDA levels were observed in 54-day-old leaves, notwithstanding leaf senescence is suggested to be a consequence of membrane deterioration due to lipid peroxidation. 
Gamma irradiation can cause genetic damage by inducing single and double strand breaks. DNA integrity was assessed with the neutral comet assay. The \% of tail DNA was, however, not significantly affected by treatment both for leaves and roots. This could imply either limited DNA damage at these relatively low dose rates or effective DNA repair mechanisms. Expression analysis of DNA repair genes is ongoing. We did not observe a significant effect of harvest time on \% tail DNA.

\section{CONCLUSIONS}

Of the parameters screened, only plant growth was significantly affected by gamma exposure dose rate and we deduced an ED-10 of $10 \mu \mathrm{Gy} \mathrm{h}{ }^{-1}$. For all other parameters analysed, including reproduction related parameters (germination) or DNA damage related parameters (Comet assay) no effect of dose rate could be observed. It hence seems difficult, if not at this stage impossible, to relate subtle effects (DNA damage, oxidative stress response) to global individual disturbances (growth and reproduction).

\section{References}

[1] Bowler, C., Slooten, L., Vandenbranden S., De Rycke R., Botterman J., Sybesma C., van Montagu M. and Inzé D., The EMBO Journal 10 (1991) 1723-1732.

[2] Mittler, R., Vanderauwera S., Gollery M. and Van Breusegem F., Trends Plant Sci. 9 (2004) 490-498.

[3] Foyer, C.H. and Noctor G., Plant Cell Environ. 28 (2005) 1056-1071.

[4] Foyer, C.H. and Noctor G., Physiol. Plant. 119 (2003) 355-364.

[5] Bergmeyer H., Gawehn K. and Grassl M., in Methods of Enzymatic Analysis, edited by H. Bergmeyer (Academic Press, New York, 1974).

[6] Imberty A., Goldberg R. and Catesson A.M., Plant Sci. Letters 35 (1984) 103-108.

[7] McCord J. and Fridovich I., J. Biol. Chem. 244 (1969) 6049-6055.

[8] Hodges D.M., Andrews C.J., Johnson D.A. and Hamilton R.I., Physiol. Plant 98 (1996) 685-692.

[9] Anderson M.E., Methods Enzymol. 113 (1985) 548-555.

[10] Dhinsda, R.S., Plumb-Dhinsda, P. and Thorpe, T.A., J. Exp. Botany 32 (1981) 93-101.

[11] Koppen G., Toncelli L.M., Triest L. and Verschaeve L., Mech. Ageing Develop. 110 (1999) 13-24.

[12] Statsoft, Inc. STATISTICA (Data analysis software system), version 6. www.stat.com (2004).

[13] Onofri, A., Riv. It. Agromet. 3 (2005) 40-45.

[14] Garnier-Laplace, J. and Gilbin R., Derivation of predicted-no-effect-dose-rate values for ecosystes (and their sub-organisational levels) exposed to radioactive substances, EC-ERICA project, Deliverable 5. www.erica-project.org (2006).

[15] Wi, S.G., Chung B.Y., Kung J.S, Kim, J.H., Baek M.H., Lee J.W. and Kim Y.S., Micro 38 (2007) $553-564$. 
